\title{
THE ROLE OF PERSON-ENVIRONMENT FIT IN MEDIATING THE EFFECTS OF COMPANY CULTURE TOWARD EMPLOYEES' TURNOVER INTENTION IN PT. BERCA HARDAYAPERKASA
}

\author{
Tinjung Desy Nursanti ${ }^{1}$; Masruroh ${ }^{2}$; Andela Putri Maharani ${ }^{3}$ \\ ${ }^{1,2,3}$ Management Department, School of Business Management, BINUS University \\ Jln. K.H. Syahdan No.9, Palmerah, Jakarta Barat 11480 \\ 1tinjungdesy@yahoo.com; ${ }^{2}$ masruroh2000@yahoo.com; ${ }^{3}$ maharaniandella@hotmail.com
}

\begin{abstract}
The purpose of this study was to investigate the mediating effect of person-environment fit on the relationship between organizational culture and staff turnover intention. Data were obtained from permanent employees who were working in unit business at PT.Berca Hardayaperkasa $(n=75)$. This research method is explanatory survey. This type of research is associative. The analysis used in this study is a path analysis. The results indicate that the organizational culture has a significant influence to the staff turnover intention and person-environment fit has a significant mediating influence on the relationship between organizational culture with staff turnover intention.
\end{abstract}

Keywords: organizational culture, person-environment fit, employee turnover intention

\begin{abstract}
ABSTRAK
Tujuan penelitian ini adalah untuk mengetahui efek dari person-environment fit sebagai variabel mediating dalam hubungan antara budaya organisasi dan intensi turnover karyawan. Data diambil dari karyawan tetap yang bekerja di unit bisnis PT. Berca Hardayaperkasa $(n=75)$. Metode penelitian ini adalah explanatory survey. Jenis penelitian ini berdasarkan tingkat eksplanasinya adalah jenis penelitian asosiatif. Analisis yang digunakan dalam penelitian ini adalah path analysis. Hasil penelitian ini menunjukkan bahwa budaya organisasi berpengaruh secara signifikan terhadap intensi tunover karyawan dan person-environment fit sebagai variabel mediating berpengaruh secara signifikan terhadap hubungan antara budaya organisasi dengan intensi turnover karyawan. (APM)
\end{abstract}

Kata kunci: budaya organisasi, person-environment fit, intensi turnover karyawan 


\section{PENDAHULUAN}

Masyarakat modern dewasa ini pada dasarnya dihadapkan dengan teknologi informasi dan komunikasi yang tentu sudah tidak asing lagi selalu berkembang dengan pesat dan menjalar di seluruh penjuru dunia serta merambah ke berbagai kalangan masyarakat. Teknologi informasi dan komunikasi mempunyai potensi peran yang sangat baik dalam memperbaiki pelaksaan organisasi di negara-negara berkembang. Teknologi informasi mampu membawa kepada peningkatan produktivitas dan efisiensi kerja yang lebih besar, serta peningkatan terhadap kuantitas dan kualitas hasil kerja organisasi. Teknologi yang cenderung dibutuhkan masyarakat luas dewasa ini harus memiliki karakteristik yang efisien, dengan kata lain dapat dimiliki dengan harga terjangkau atau murah, dapat diakses dengan cepat, memiliki nilai tambah dan berujung pada peningkatan kualitas kinerja sumber daya manusia. Walau demikian peran masyarakat juga sangat penting dalam menghidupkan dan mewujudkan teknologi yang dibutuhkan saat ini. Dalam hal ini masyarakat harus menjadi pelaku pembangunan itu sendiri melalui pengembangan kompetensi dalam memanfaatkan informasi dan teknologi.

Salah satu perusahaan yang bergerak di bidang teknologi informasi adalah PT. Berca Hardayaperkasa yang sering disebut BHp, dan merupakan salah satu anak perusahaan dari PT. Berca Indonesia yang berdiri pada tahun 1973. PT. BHp sendiri berdiri pada tahun 1992. PT. Berca Hardayaperkasa (BHp) telah menjadi salah satu penyedia terkemuka dalam bidang Information Technology (IT), Test \& Measurement (T\&M) di Indonesia. Ir Edwin Notokusumo selaku GM Consulting menyatakan bahwa keberhasilan perusahaan pada dasarnya tidak lepas dari pengelolaan tenaga kerjanya sebagai aset utama bagi sebuah perusahaan yang berperan dalam menggerakkan roda bisnis perusahaan. Tanpa kehadiran tenaga kerja, perusahaan akan mengalami kesulitan dalam menjalankan bisnisnya. Sebuah perusahaan harus memiliki kemampuan dalam mengelola sumber daya manusia karena suatu perusahaan dihadapkan pada risiko ditinggalkan oleh para tenaga ahlinya.

Hal tersebut bukan sebuah fenomena yang baik karena perusahaan dapat kehilangan aset yang sangat berharga. Kondisi ini patut menjadi fokus utama manajemen perusahaan karena kekurangan tenaga kerja ahli dapat mengganggu produktivitas dan merugikan perusahaan. Situasi ini kerap diperburuk dengan kecenderungan tenaga kerja untuk berganti pekerjaan dalam kurun waktu kurang dari satu tahun daripada mengembangkan karir di sebuah perusahaan. Kecenderungan niat karyawan keluar dari suatu organisasi disebut juga dengan intensi turnover karyawan.

Intensi turnover karyawan merupakan hal yang tidak dikehendaki perusahaan karena dapat merugikan perusahaan karena biaya yang besar dan harus dikeluarkan untuk proses rekrutmen, seleksi karyawan baru dan biaya pelatihan karyawan. Banyak faktor yang mampu mendorong terjadinya intensi turnover, salah satu yang paling mempengaruhi adalah budaya organisasi. Mengacu pada pendapat Robbins (2006) bahwa budaya adalah alat yang dapat menstabilkan keadaan pada suatu organisasi dan mempunyai pengaruh yang bermakna pada sikap dan perilaku anggotanya sehingga budaya memiliki pengaruh yang kuat dengan tingkah laku seseorang.

Selain itu faktor yang memungkinkan masalah intensi turnover terjadi adalah kesesuaian individu dengan lingkungan atau person-environment fit. Hal ini dicerminkan oleh keserasian antara nilai-nilai yang dianut dalam diri dengan yang ada di tempat kerja (person-organization fit), antara kemampuan dan keterampilan yang dimiliki dengan tuntutan kerja (person-job fit), antara orang dengan tim kerja (person-group fit) atau antara kebutuhan (seperti gaji, tunjangan, pelatihan) dengan kompensasi yang dapat diberikan oleh organisasi/perusahaan sebagai kontribusi kepada perusahaan (need-supply fit). Sejumlah situasi yang dipaparkan di atas, juga menjadi masalah yang dihadapi PT. BHp karena banyak karyawan yang keluar dari perusahaan secara sukarela sehingga dapat disimpulkan bahwa banyak intensi turnover dari karyawan dalam perusahan ini yang berujung pada 
terjadinya turnover karyawan. Oleh karena itu, penelitian ini dilakukan untuk mengetahui apakah budaya organisasi merupakan faktor yang memengaruhi intensi turnover karyawan di PT BHp dan apakah antara hubungan budaya organisasi dengan intensi turnover karyawan PT BHp dimediasi oleh pengaruh person-environment fit.

Rumusan masalah penelitian ini adalah untuk mengetahui apakah ada pengaruh budaya organisasi secara signifikan terhadap intensi turnover karyawan di PT BHp dan apakah ada pengaruh person-environment fit secara signifikan sebagai variabel mediating pada hubungan antara budaya organisasi dengan intensi turnover karyawan di PT BHp. Tujuan penelitian ini adalah untuk mengetahui ada atau tidak pengaruh signifikan budaya organisasi terhadap intensi turnover karyawan di PT BHp dan pengaruh signifikan person-environment fit sebagai variabel mediasi pada hubungan antara budaya organisasi dengan intensi turnover karyawan di PT BHp.

Penelitian Ahmad (2012) bertujuan untuk mencari efek dari person-environment fit dalam hubungan budaya organisasi dan intensi turnover karyawan. Hasil penelitian ini adalah personenvironment fit memediasi secara signifikan pada hubungan antara budaya organisasi dengan intensi turnover karyawan dengan menggunakan analisa regresi. Macintosh dan Doherty (2010) melakukan penelitian yang bertujuan untuk menghasilkan dampak dari budaya organisasi, dan kepuasan kerja terhadap intensi karyawan untuk meninggalkan organisasi. Budaya organisasi merupakan nilai, kepercayaan, dan membantu memandu asumsi dasar dan mengkordinasi tingkah laku anggota organisasi. Penelitian ini dilakukan menggunakan analisa path analysis untuk mengukur hubungan antara faktor budaya organisasi, kepuasan kerja dan niat untuk keluar. Hasil penelitian ini menjelaskan $14,3 \%$ dari varian budaya organisasi dan $50,3 \%$ dari kepuasan kerja yang membuat adanya intensi untuk meninggalkan organisasi.

Penelitian ini memiliki nilai lebih dari penelitian sebelumnya, penelitian ini menggunakan analisis path analisys yang dapat lebih mengukur nilai koefisien jalur antar variabelnya, sehingga dapat diketahui ada tidaknya pengaruh langsung maupun pengaruh tidak langsung atas variabel penelitian ini.

\section{Budaya Organisasi}

Kreitner \& Kinichi (2007) mengungkapkan bahwa budaya organisasi juga dapat difungsikan sebagai identitas organisasi, komitmen kolektif, stabilitas sistem dan sebagai alat yang memberikan pengertian. Lebih lanjut, Robbins \& Coulter (2012) memaparkan tujuh karakteristik atau dimensi budaya organisasi yang meliputi: (1) Inovasi dan keberanian mengambil risiko, dan bagaimana organisasi menghargai tindakan pengambilan risiko oleh karyawan dan membangkitkan ide karyawan. (2) Perhatian terhadap detail, yaitu sejauh mana organisasi mengharapkan karyawan memperlihatkan kecermatan, analisis dan perhatian kepada rincian. (3) Berorientasi kepada hasil, yaitu sejauh mana manajemen memusatkan perhatian pada hasil dibandingkan perhatian pada teknik dan proses yang digunakan. (4) Berorientasi kepada manusia, yaitu sejauh mana keputusan manajemen memperhitungkan efek hasil-hasil pada orang-orang di dalam organisasi. (5) Berorientasi tim, yaitu sejauh mana kegiatan kerja diorganisasikan sekitar tim-tim, bukan individu-individu. (6) Sikap agresif, menunjukkan sejauh mana orang-orang dalam organisasi itu agresif dan kompetitif untuk menjalankan budaya organisasi sebaik-baiknya. (7) Stabilitas, yaitu adalah sejauh mana kegiatan organisasi menekankan status quo (mempertahankan apa yang ada karena dianggap sudah cukup baik) daripada pertumbuhan.

\section{Intensi Turnover}

Intensi turnover dapat dijelaskan sebagai sikap yang mempengaruhi niat untuk berhenti dan benar-benar berhenti dari organisasi. Bockermann dan Ilmakunnas dalam Sinem \& Baris (2011) 
mendefinisikan intensi turnover sebagai sikap perilaku seseorang untuk menarik diri dari organisasi, sedangkan turnover dianggap sebagai pemisahan yang sebenarnya dari organisasi. Adapun Novliadi (2007) menjelaskan intensi turnover adalah kecenderungan atau niat karyawan untuk berhenti bekerja dari pekerjaannya secara sukarela menurut pilihannya sendiri. Dari definisi di atas dapat disimpulkan bahwa intensi turnover karyawan adalah keinginan dari dalam diri karyawan itu sendiri untuk pergi meninggalkan organisasinya dan mungkin mencari pekerjaan lain yang lebih baik.

\section{Pengertian Person-Environment Fit}

Menurut Kristof dalam Ahmad (2011), Person-Environtment Fit (P-E fit) didefinisikan sebagai sejauh mana individu dan lingkungan memiliki kecocokan. Adapun Edwards dalam Ahmad (2012) memaparkan bahwa P-E fit mengacu pada tingkat kecocokan atau kesesuaian antara karakteristik pribadi dan karakteristik lingkungan kerja. Secara konsisten P-E fit berkaitan dengan sejumlah sikap yang berhubungan dengan pekerjaan dan perilaku seperti kepuasan, komitmen terhadap organisasi. Oleh karena itu, P-E fit merupakan kesesuaian antara apa yang dimiliki oleh kesesuaian antara kebutuhan dari setiap individu dengan hal-hal yang diberikan oleh organisasinya.

Edward dan Billsberry dalam Ahmad (2012) meneliti P-E fit dari tiga perspektif: (1) PersonJob Fit. Kesesuaian antara individu dengan pekerjaan yang sedang dijalankan. (2) PersonOrganization Fit. Kesesuaian antara nilai yang dianut individu dengan apa yang dianut organisasi tempat mereka bekerja. (3) Person-Group Fit. Kesesuaian antara individu dengan kelompok atau tim kerja.

\section{METODE}

Jenis penelitian ini adalah asosiatif yaitu jenis penelitian yang digunakan untuk mengetahui pengaruh dan juga hubungan dua variabel atau lebih. Metode penelitian ini adalah explanatory survey atau penelitian ini diawali dengan survei langsung terhadap perusahaan yang menjadi objek penelitian. Jenis dan sumber data penelitian sesuai dengan tujuan penelitian yang terdiri dari data kualitatif dan kuantatif. Data kualitatif adalah data berupa kata, kalimat, dan gambar sedangkan data kuantitatif adalah data berupa angka atau data kualitatif yang dijabarkan dalam angka. Adapun sumber data yang dikumpulkan dapat dibedakan menjadi data primer dan data sekunder (Hair, 2010).

Budaya organisasi diukur dengan menggunakan 7 sub variabel atau dimensi dari Robbin \& Coulter (2012): (1) Inovasi dan pengambilan risiko, yaitu sejauh mana karyawan didorong untuk inovatif dan mengambil risiko. (2) Perhatian kerincian, yaitu sejauh mana karyawan diharapkan memperlihatkan kecermatan. (3) Orientasi hasil, yaitu sejauh mana manajemen memusatkan perhatian pada hasil bukan pada teknik dan proses untuk mencapai hasil tersebut. (4) Orientasi orang, yaitu sejauh mana keputusan manajemen memperhatikan efek dari hasil terhadap orang-orang didalam organisasi. (5) Orientasi tim, yaitu sejauh mana kegiatan kerja diorganisasikan pada tim bukan individu. (6) Keagresifan, yaitu sejauh mana orang-orang agresif dan kompetitif. (7) Kemantapan, yaitu sejauh mana organisasi mempertahankan apa yang ada karena dianggap sudah cukup baik daripada pertumbuhan.

Intensi turnover karyawan diukur dengan menggunakan 3 sub variabel atau dimensi dari Cammann, Fichman, Jenkins dan Klesh dalam Ahmad (2012) yang meliputi: (1) Thinking of quit, yaitu karyawan mempunyai pikiran untuk keluar dari pekerjaannya. (2) Intention to search, yaitu karyawan mempunyai niat untuk mencari pekerjaan lain. (3) Intention to quit, yaitu karyawan memiliki niat untuk meninggalkan organisasi. 
Person-environment fit diukur dengan menggunakan 3 sub variabel atau dimensi dari Edward dan Billsberry (2010) yang terdiri atas: (1) Person-Organization Fit, yaitu kesesuaian individu dengan organisasinya. (2) Person-Job Fit, yaitu kesesuaian individu dengan pekerjaannya. (3) Person-Group Fit, yaitu kesesuaian individu dengan tim kerjanya.

Data diambil dari penyebaran kuesioner terhadap karyawan tetap PT. Berca Hardayaperkasa sebanyak 75 responden. Jumlah responden didapat dari menyederhanakan populasi dengan rumus slovin. Analisis yang digunakan dalam penelitian ini adalah path analysis, yang digunakan untuk mengetahui pengaruh langsung dan tidak langsung (Riduwan dan Kuncoro, 2007).

\section{HASIL DAN PEMBAHASAN}

Dalam analisis path analysis langkah pertama yang dilakukan adalah menguji secara partial untuk melihat adakah pengaruh signifikan budaya organisasi sebagai variabel bebas terhadap intensi turnover karyawan sebagai variabel tergantung.

Tabel 1 Coefficients Model - 1

Coefficients $^{\mathrm{a}}$

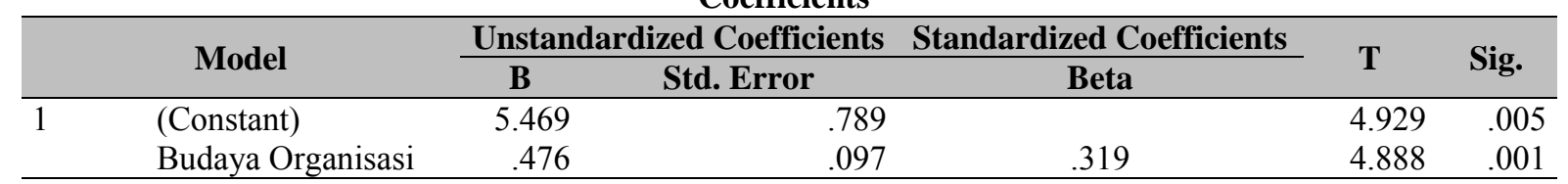

a. Dependent Variable: Intensi Turnover Karyawan

Sumber: Data kuesioner yang telah diolah (2013)

Berdasarkan hasil pengolahan data diperoleh nilai $\mathrm{t}_{\text {hitung }}$ sebesar 4,888 dan $\mathrm{t}_{\text {tabel }}$ yang didapat dari rumus $n-k$ atau 75-3 $=72$ dengan $a=5 \%$ adalah sebesar 1,666. Dengan demikian dapat diketahui bahwa nilai $t_{\text {hitung }}>t_{\text {tabel }}(4,888>1,666)$ yang artinya ada pengaruh antara budaya organisasi terhadap intensi turnover karyawan. Tingkat signifikansi dapat dilihat pada kolom (Sig.) dimana nilai signifikansi yang diperoleh lebih kecil dari $0,05(0,001<0,05)$ yang artinya pengaruh dianggap signifikan. Besarnya pengaruh variabel budaya organisasi terhadap intensi turnover karyawan sebesar 0,319 atau sebesar $31,9 \%$.

Selanjutnya dilakukan analisa pengaruh person-environment fit sebagai variabel mediating terhadap hubungan budaya organisasi dengan intensi turnover karyawan. Analisa ini digunakan untuk melihat apakah person-environment fit benar-benar menjadi variabel mediating terhadap hubungan budaya organisasi dengan intensi turnover karyawan.

Tabel 2 Model Summary-1

\begin{tabular}{|c|c|c|c|c|c|c|c|}
\hline \multirow{3}{*}{ Model } & \multirow[b]{3}{*}{$\mathbf{R}$} & \multirow{3}{*}{ R Square } & \multicolumn{2}{|c|}{ Model Summary } & \multirow{2}{*}{\multicolumn{3}{|c|}{ Change Statistics }} \\
\hline & & & Adjusted & Std. Error of & & & \\
\hline & & & R Square & the Estimate & R Square Change & F Change & df1 \\
\hline 1 & $.759^{\mathrm{a}}$ & .576 & .068 & 1.359737 & 319 & .765 & 2 \\
\hline
\end{tabular}

a. Predictors: (Constant) Person-Environment fit, Budaya organisasi

b. Dependent Variabel: Intensi Turnover Karyawan

Sumber: Data kuesioner yang telah diolah (2013) 
Tabel 3 Coefficients Model-2

Coefficients $^{\text {a }}$

\begin{tabular}{lcccccc}
\hline \multirow{2}{*}{ Model } & \multicolumn{2}{c}{ Unstandardized Coefficients } & Standardized Coefficients & \multirow{2}{*}{ t } & Sig. \\
\cline { 3 - 5 } & B & Std. Error & Beta & & \\
\hline 1 & (Constant) & 5.469 & .789 & & 1.929 & .005 \\
& Budaya Organisasi & .679 & .081 & .836 & 6.994 & .000 \\
\hline
\end{tabular}

Sumber: Data kuesioner yang telah diolah (2013)

Tabel 4 Model Summary-2

Model Summary

\begin{tabular}{cccccccc}
\hline \multirow{2}{*}{ Model } & \multirow{2}{*}{$\mathbf{R}$} & \multirow{2}{*}{ R Square } & \multirow{2}{*}{$\begin{array}{c}\text { Adjusted } \mathbf{R} \\
\text { Square }\end{array}$} & $\begin{array}{c}\text { Std. Error of the } \\
\text { Estimate }\end{array}$ & \multicolumn{3}{c}{ Change Statistics } \\
\cline { 6 - 8 } & & & & R Square Change & F Change & df1 \\
\hline 1 & $.836^{\mathrm{a}}$ & .698 & .323 & 1.360702 & .318 & .425 & 1 \\
\hline
\end{tabular}

a. Predictors: (Constant), Person-Environment fit

b. Dependent Variable: Intensi Turnover Karyawan

Sumber: Data kuesioner yang telah diolah (2013)

Tabel 5 Coefficients Model -3

Coefficients $^{\mathrm{a}}$

\begin{tabular}{|c|c|c|c|c|c|c|}
\hline \multirow{2}{*}{\multicolumn{2}{|c|}{ Model }} & \multicolumn{2}{|c|}{ Unstandardized Coefficients } & \multirow{2}{*}{$\begin{array}{c}\text { Standardized Coefficients } \\
\text { Beta }\end{array}$} & \multirow{2}{*}{$\mathbf{t}$} & \multirow{2}{*}{ Sig. } \\
\hline & & B & Std. Error & & & \\
\hline \multirow[t]{3}{*}{1} & (Constant) & 6.281 & 1.104 & & 5.689 & .000 \\
\hline & Budaya Organisasi & -.131 & .032 & -.115 & -.941 & .350 \\
\hline & Person-Environment fit & .650 & .248 & .829 & 3.051 & .008 \\
\hline
\end{tabular}

a. Dependent Variable: Intensi Turnover Karyawan

Sumber: Data kuesioner yang telah diolah (2013)

Dari tabel-tabel di atas diperoleh nilai koefisien jalur $\mathrm{X}$ terhadap $\mathrm{Y}$ sebesar $(0,319), \mathrm{X}$ terhadap M sebesar $(0,836)$, dan M terhadap Y (0,829). Adapun berdasarkan hasil output pada tabel 4 koefisien jalur $\mathrm{X}$ menurun menjadi $(-0,115)$ setelah dimasukkan variabel mediating. Kemudian mengacu pada tabel model summary $-1 \& 2$ pada kolom R Square didapat nilai sebesar $(0,576) \&$ $(0,698)$ dari kedua nilai tersebut dapat dihitung nilai koefisien residual untuk variable $\mathrm{M}$ dan $\mathrm{Y}$ (residual adalah selisih antara nilai duga dengan nilai pengamatan sebenarnya) perhitungan sebagai berikut: $\sqrt{ } 1-0,698=0,549$ dibulatkan menjadi 0,55 nilai ini adalah besar koefisien residual variable M. $\sqrt{ } 1-0,576=0,651$ nilai ini adalah besar koefisien residual variabel $\mathrm{Y}$.

\section{SIMPULAN}

Uji hipotesis pertama menunjukkan bahwa Ha diterima dan ini berarti bahwa budaya organisasi berpengaruh secara signifikan terhadap intensi turnover karyawan dengan pengaruh sebesar 31,9\%. Uji hipotesis kedua juga menunjukkan bahwa Ha diterima dan ini berarti bahwa person environment fit sebagai variabel mediating berpengaruh secara signifikan terhadap hubungan budaya organisasi dengan intensi turnover karyawan. Sehubungan dengan hasil penelitian tersebut, dapat dijelaskan bahwa ada baiknya perusahaan melakukan perubahan budaya organisasi agar karyawan dapat lebih termotivasi, nyaman, dan bersemangat. Perusahaan juga harus dapat meningkatkan 
kesesuaian karyawan dengan lingkungannya, diantaranya dapat dilakukan dengan cara memperbaiki fasilitas kantor menjadi senyaman mungkin, menyelaraskan visi dan misi perusahaan dengan karyawan, dan dengan cara melakukan sharing atau bermusyawarah. Selain itu, perusahaan juga sebaiknya mengedepankan gaya kepeminpinan concern for people, gaya kepemimpinan ini memprioritaskan kebutuhan, kepentingan, serta menangani masalah-masalah yang terjadi pada karyawan.

\section{DAFTAR PUSTAKA}

Ahmad, K. Z., Veerapandian, K., Wee, Y. G. (2011). Person-Environment Fit: The Missing Link in the Organisational Culture-Commitment Relationship. International Journal of Business and Management, 6(11).

Ahmad, K. Z. (2012). The Mediating Effect of Person-Environment Fit on the Relationship between Organisational Culture and Staff Turnover. Journal of Asian Social Science, 8(2): 62-71.

Edwards, J. R., Billsberry, J. (2010). Testing a Multidimensional Theory of Person-Environment Fit. Journal of Managerial Issues, 22(4): 476-493.

Hair, J. F. (2010). Multivariate data analysis. (7th edition). New Jersey: Pearson Education Inc.

Kreitner, R., Kinicki, A. (2007). Organizational Behaviour. Ninth Edition. Arizona: McGraaw-Hill, Inc.

MacIntosh, E. W., Doherty, A. (2010). The influence of organizational culture on job satisfaction and intention to leave. Sport Management Review, 13: 106-117.

Novliadi, F. (2007). Intensi Turnover Karyawan ditinjau dari Budaya Perusahaan dan Kepuasan Kerja. Makalah. Diakses dari library.usu.ac.id/ download/ fk/ 132316960.pdf.

Robbins, S. P., Coulter, M. (2012). Management, $11^{\text {th }}$ Edition. New Jersey: Pearson Education, Inc.

Robbins, S. P. (2006). Perilaku Organisasi. Edisi Kesembilan. Jakarta: PT. Indeks Kelompok Gramedia.

Riduwan dan Kuncoro, E. A. (2007). Cara Menggunakan dan Memaknai Analisis Jalur (Path Analysis). Bandung: Alfabeta.

Sinem, A., Baris, A. (2011). An Empirical Study of the Relationship Among Job Satisfaction, Organizational Commitment and Turnover Intention, International Review of Management and Marketing, 1(3): 43-53. 